\title{
Effect of rhubarb on extravascular lung water in patients with acute respiratory distress syndrome
}

\author{
Jianxin He ${ }^{1 *}$, Xiaoshui Si ${ }^{1}$, MingXia J। ${ }^{1}$, Jing Huang ${ }^{1}$, Wenjuan Zheng ${ }^{1}$, Jiao Wang ${ }^{1}$, Junfeng Wang ${ }^{1}$, LiJun Zhu $^{1}$

Study conducted at Critical Care Medicine, Yiwu Central Hospital, Yiwu, Zhejiang Province, China

Article received: $11 / 9 / 2016$ Accepted for publication: 12/4/2016 *Correspondence: Critical Care Medicine, Yiwu Central Hospital, Address: No. 699 Jiangdong Road Yiwu, Zhejiang Province - China Postal code: 322000 jxcndoc@163.com

\section{SUMMARY}

Objective: The aim of this study was to evaluate the effect of rhubarb on extravascular lung water (EVLW) in patients with acute respiratory distress syndrome (ARDS).

Method: A total of 80 patients with ARDS were randomly divided into a treatment group (40 cases) and control group (40 cases). Patients in the treatment group received rhubarb $(30.0 \mathrm{~g} / \mathrm{d})$ and patients in the control group received conventional therapy for seven consecutive days. Extravascular lung water index (EVLWI) and pulmonary vascular permeability index (PVPI) were determined using pulse contour cardiac output (PiCCO) technology, and the oxygenation index was measured by blood gas analysis at baseline and on days 3, 5 and 7 after treatment.

Results: The oxygenation index was higher and the levels of EVLWI and PVPI were lower after treatment in the two groups; however, these indexes showed significant differences on the $5^{\text {th }}$ and $7^{\text {th }}$ days after rhubarb treatment compared with the results in the control group $(\mathrm{p}<0.05)$.

Conclusion: Rhubarb can decrease EVLWI and PVPI, and improve oxygenation in patients with ARDS.

Keywords: rhubarb, ARDS, EVLWI, oxygenation index.

\section{INTRODUCTION}

The mortality rate in acute respiratory distress syndrome (ARDS) is as high as $40 \%,{ }^{1}$ and is a major cause of death in intensive care unit (ICU) patients. ${ }^{2}$ Therefore, research on the pathogenesis of ARDS and the development of effective new drugs for the treatment of ARDS are very important. Although the causes of ARDS are complex, the basic mechanism in the development of ARDS involves the alveolar capillary epithelium (ACM) and alveolar epithelial injury caused by abnormal inflammatory responses. ${ }^{3,4}$ In the treatment of the primary disease, almost all measures used to inhibit the inflammatory response, including the use of cytokine monoclonal antibodies and free radical scavenging agents, failed in clinical trials. ${ }^{5,6}$ Few effective drugs have been found to improve alveolar capillary permeability, reduce extravascular lung water (EVLW), and improve oxygenation. ${ }^{7-9}$ Studies using tra- ditional Chinese medicine and traditional Chinese and Western Integrative Medicine have explored methods for the effective treatment of ARDS..$^{10,11}$ The effect of rhubarb on EVLW in patients with ARDS has not been reported (Zhejiang Science and Technology Information Research Institute. Science and Technology Novelty Search Report, No. 201533B2108291), but the study provided a theoretical basis for the clinical use of rhubarb in the treatment of ARDS. Moreover, the pulse contour cardiac output (PiCCO) technology used in the project to monitor hemodynamics was mature, low-risk and less expensive. ${ }^{12}$ Timely monitoring of EVLW dynamics can quantitatively reflect ACM injury and pulmonary edema, and was helpful in the observation and assessment of ARDS; EVLW monitoring is easily implemented in clinical settings. ${ }^{12}$

Our randomized controlled study examined the effect of rhubarb on EVLW and the oxygenation index at dif- 
ferent time points in patients with ARDS. Effective means of treating ARDS using Chinese medicine were explored, with the expectation of further improvement in the success rate through the application of Chinese and Western Integrative Medicine.

\section{Method}

\section{Selection of cases}

Eighty patients with ARDS who met the inclusion criteria in our department from January 2012 to June 2014 were randomly divided into a treatment group (rhubarb + conventional treatment, 40 cases) and a control group (conventional treatment, 40 cases); there were 47 males and 33 females aged 22-79 years, with mean age of 58.4 years. Of these, six had severe pancreatitis, 15 had pulmonary infections, 13 had abdominal infections, ten had multiple injuries, and 36 had sepsis. Our study was conducted in accordance with the declaration of Helsinki and was approved by the Ethics Committee of Yiwu Central Hospital. Written informed consent was obtained from all participants.

\section{Inclusion and exclusion criteria}

Inclusion criteria were based on the 2011 Berlin consensus definition of ARDS: ${ }^{13,14}$ 1) a, time: according to onset after the cause is identified, or with emerging/existing respiratory symptom aggravation within a week; $b$, image changes: lung transmittance reduced, not completely explained by pleural effusion, atelectasis or lung nodules; c, causes of pulmonary edema: cannot be interpreted as heart failure or fluid overload; $d$, oxygenation: mild, $200 \mathrm{mmHg}$ < oxygenation index $\leq 300 \mathrm{mmHg}$ when PEEP (positive end-expiratory pressure)/CPAP (continuous positive airway pressure) $\geq 5 \mathrm{cmH}_{2} \mathrm{O}$; moderate, $100 \mathrm{mmHg}$ $<$ oxygenation index $\leq 200 \mathrm{mmHg}$ when PEEP/CPAP $\geq$ $5 \mathrm{cmH}_{2} \mathrm{O}$; severe, oxygenation index $\leq 100 \mathrm{mmHg}$ when $\mathrm{PEEP} / \mathrm{CPAP} \geq 5 \mathrm{cmH}_{2} \mathrm{O} ; 2$ ) endotracheal intubation and mechanical ventilation more than $24 \mathrm{~h}$; 3 ) intra-abdominal pressure $<20 \mathrm{mmHg}$. Exclusion criteria: 1) patients with advanced cancer; 2 ) preexisting chronic diseases in the heart, lung, liver, kidney or other organs; 3 ) blood diseases; 4) immunosuppressed patients.

\section{Design and treatment programs}

Within 24 hours after being admitted, the treatment group received $10.0 \mathrm{~g}$ of cooling rhubarb leachate extracted with $30 \mathrm{~mL}$ of boiling water via nasogastric tube instillation at appropriate temperature, plus conventional treatment, three times a day for seven days. The control group received conventional treatment. Conven- tional treatments included endotracheal intubation, mechanical ventilation, fluid therapy, anti-infective therapy and nutritional support.

\section{Clinical indicators}

The selected patients underwent placement of a pulse contour cardiac output (PiCCO) catheter (PV2014L16; PULSION, Germany) through the femoral artery for continuous monitoring. Thermal dilution methods were used to determine extravascular lung water index (EVLWI) and pulmonary vascular permeability index (PVPI) changes in patients at baseline and on days 3, 5 and 7 after treatment. A blood gas analyzer (GEM Premier3000) was used to detect arterial oxygen changes, and the oxygenation indexes of the two groups were compared.

\section{Statistical analysis}

SPSS 18.0 software package was used for statistical analysis of the data. Measurement data were expressed as mean \pm standard deviation $(\bar{\chi} \pm s)$; comparisons between measurement data for the two groups were performed using a t-test. Numerical data were compared using the $\chi^{2}$ test. The differences between groups were compared using analysis of variance (ANOVA), and further pairwise comparisons were performed using the least significant difference test. $\mathrm{p}<0.05$ indicated that the difference was statistically significant.

\section{Results}

General clinical data and causes of disease

The differences in age, sex, weight, height, acute physiology and chronic health evaluation (APACHE) II score, and PEEP between the rhubarb treatment group and control group were not statistically significant ( $p>0.05$; Table 1 ).

\section{Changes in EVLW and vascular permeability before and} after treatment

EVLWI and PVPI in the two groups showed no significant difference before treatment $(\mathrm{F}=0.36,0.42, \mathrm{p}>0.05)$. Three, five and seven days after treatment, EVLWI and PVPI in both groups declined to various degrees $(\mathrm{F}=0.63,0.56$; $\mathrm{p}<0.05)$; the differences on further pairwise comparisons were statistically significant $(p<0.05)$. The EVLWI and PVPI of patients in the treatment group were significantly lower than those of the control group on the $5^{\text {th }}(\mathrm{F}=0.70$, $0.42, \mathrm{p}<0.05)$ and 7 th days $(\mathrm{F}=0.84,0.35, \mathrm{p}<0.05)$ after treatment (Table 2, Figure 1, Figure 2).

\section{Changes in oxygenation before and after treatment}

The oxygenation index in both groups showed no significant difference before treatment $(\mathrm{F}=0.35, \mathrm{p}>0.05)$. 
Three, five and seven days after treatment, the oxygenation index of the patients in both groups increased to various degrees $(\mathrm{F}=1.09, \mathrm{p}<0.05)$, the differences on further pairwise comparison were statistically significant $(\mathrm{p}<0.05)$. The oxygenation index of patients in the treatment group on the $5^{\text {th }}$ day $(\mathrm{F}=0.39, \mathrm{p}<0.05)$ and $7^{\text {th }}$ day $(\mathrm{F}=1.08, \mathrm{p}<0.05)$ after treatment was significantly higher than that of the control group (Table 2, Figure 3).

\section{Discussion}

ARDS is a complex disorder. First proposed in 1967, the mortality rate has been as high as $75 \%$. In the past 40 years,

\section{TABLE 1 Comparison of patient data between the treatment and control groups.}

\begin{tabular}{lllllllll} 
Group & $\begin{array}{l}\text { Cases } \\
(\mathbf{n})\end{array}$ & $\begin{array}{l}\text { Sex } \\
(\text { male/female) }\end{array}$ & $\begin{array}{l}\text { Age } \\
(\text { years old) }\end{array}$ & $\begin{array}{l}\text { Weight } \\
(\mathbf{k g})\end{array}$ & $\begin{array}{l}\text { Height } \\
\mathbf{( \mathbf { c m } )}\end{array}$ & $\begin{array}{l}\text { PEEP } \\
\left(\mathbf{c m} \mathbf{H}_{\mathbf{2}} \mathbf{O}\right)\end{array}$ & $\begin{array}{l}\text { APACHE II } \\
\text { score (points) }\end{array}$ & $\begin{array}{l}\text { Oxygenation } \\
\text { index }\end{array}$ \\
\hline Treatment group & 40 & $25 / 15$ & $(59 \pm 12)$ & $65 \pm 7$ & $168 \pm 10$ & $9.8 \pm 2.5$ & $19.5 \pm 2.5$ & $115 \pm 26$ \\
\hline Control group & 40 & $22 / 18$ & $(57 \pm 10)$ & $68 \pm 6$ & $170 \pm 10$ & $10.5 \pm 2.4$ & $19.8 \pm 2.3$ & $110 \pm 27$ \\
\hline$\chi^{2}$ value & & 0.22 & 0.18 & 0.11 & 0.82 & 1.58 & 0.64 & 0.06 \\
\hline -value & 0.45 & 0.67 & 0.74 & 0.417 & 0.21 & 0.43 & 0.81 \\
\hline
\end{tabular}

Note: APACHE (acute physiology and chronic health evaluation) II score.

TABLE 2 Changes in EVLW/vascular permeability and oxygenation index of patients before and after treatment between the two groups $(\bar{\chi} \pm s)$.

\begin{tabular}{|c|c|c|c|c|c|c|}
\hline Index & Group & $\begin{array}{l}\text { Cases } \\
(\mathrm{n})\end{array}$ & $\begin{array}{l}\text { Baseline } \\
\text { (pre-treatment) }\end{array}$ & $\begin{array}{l}\text { Day } 3 \text { after } \\
\text { treatment }\end{array}$ & $\begin{array}{l}\text { Day } 5 \text { after } \\
\text { treatment }\end{array}$ & $\begin{array}{l}\text { Day } 7 \text { after } \\
\text { treatment }\end{array}$ \\
\hline \multirow[t]{2}{*}{ EVLWI (mL/kg) } & Treatment group & 40 & $12.4 \pm 4.1$ & $9.5 \pm 3.8$ & $6.3 \pm 2.6^{\mathrm{a}, \mathrm{b}}$ & $4.7 \pm 2.2^{\mathrm{a}, \mathrm{b}}$ \\
\hline & Control group & 40 & $11.7 \pm 4.8$ & $9.3 \pm 4.1$ & $8.4 \pm 2.7^{\mathrm{a}}$ & $7.1 \pm 1.9^{a}$ \\
\hline \multirow[t]{2}{*}{ PVPI } & Treatment group & 40 & $6.0 \pm 0.8$ & $4.6 \pm 1.4$ & $2.8 \pm 0.9^{a, b}$ & $1.7 \pm 0.8^{a, b}$ \\
\hline & Control group & 40 & $5.0 \pm 0.9$ & $4.7 \pm 1.2$ & $3.8 \pm 0.8^{\mathrm{a}}$ & $2.7 \pm 0.7^{a}$ \\
\hline \multirow{2}{*}{$\begin{array}{l}\text { Oxygenation index } \\
(\mathrm{mmHg})\end{array}$} & Treatment group & 40 & $115 \pm 24$ & $128 \pm 31^{\mathrm{a}}$ & $186 \pm 32^{a, b}$ & $294 \pm 51^{a, b}$ \\
\hline & Control group & 40 & $113 \pm 25$ & $125 \pm 32^{\mathrm{a}}$ & $167 \pm 27^{a}$ & $212 \pm 50^{\mathrm{a}}$ \\
\hline
\end{tabular}

EVLWI: extra vascular lung water index; PVPI: pulmonary vascular permeability index.

Compared with baseline (pre-treatment), ${ }^{\mathrm{a}} \mathrm{p}<0.05$; compared with the control group, ${ }^{\mathrm{b}} \mathrm{p}<0.05$.

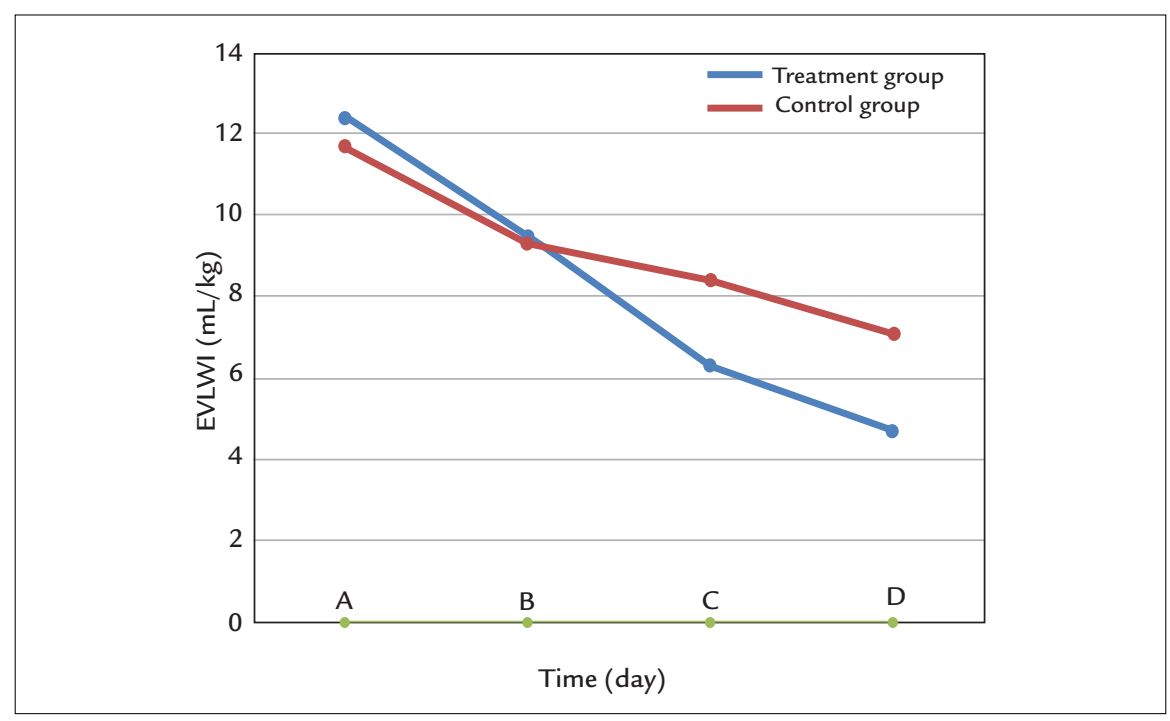

FIGURE 1 Changes in EVLWI ( $\mathrm{mL} / \mathrm{kg})$ in patients before and after treatment between the two groups. A. Before treatment; B. Three days after treatment; C. Five days after treatment; D. Seven days after treatment. 


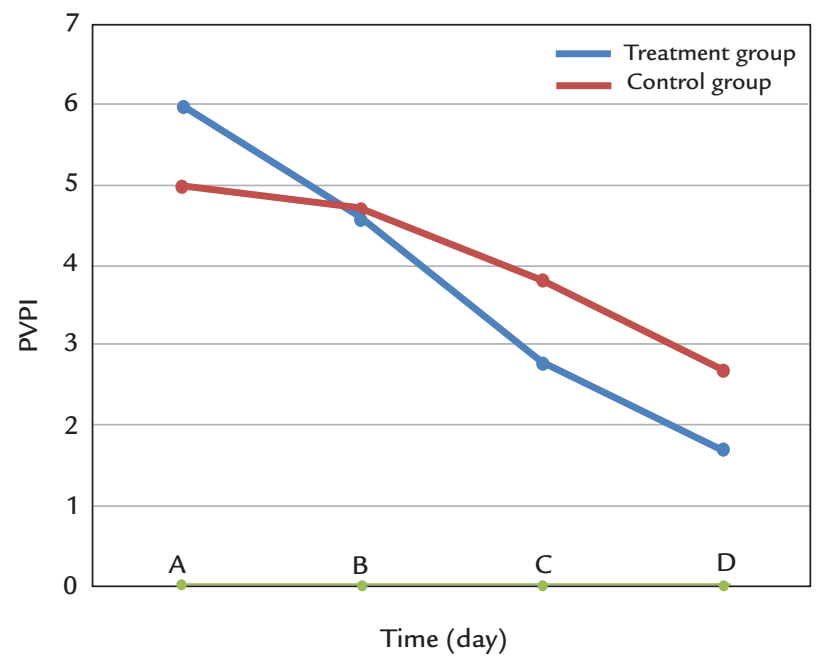

FIGURE 2 Changes in vascular permeability in patients before and after treatment between the two groups. A. Before treatment; B. Three days after treatment; C. Five days after treatment; D. Seven days after treatment.

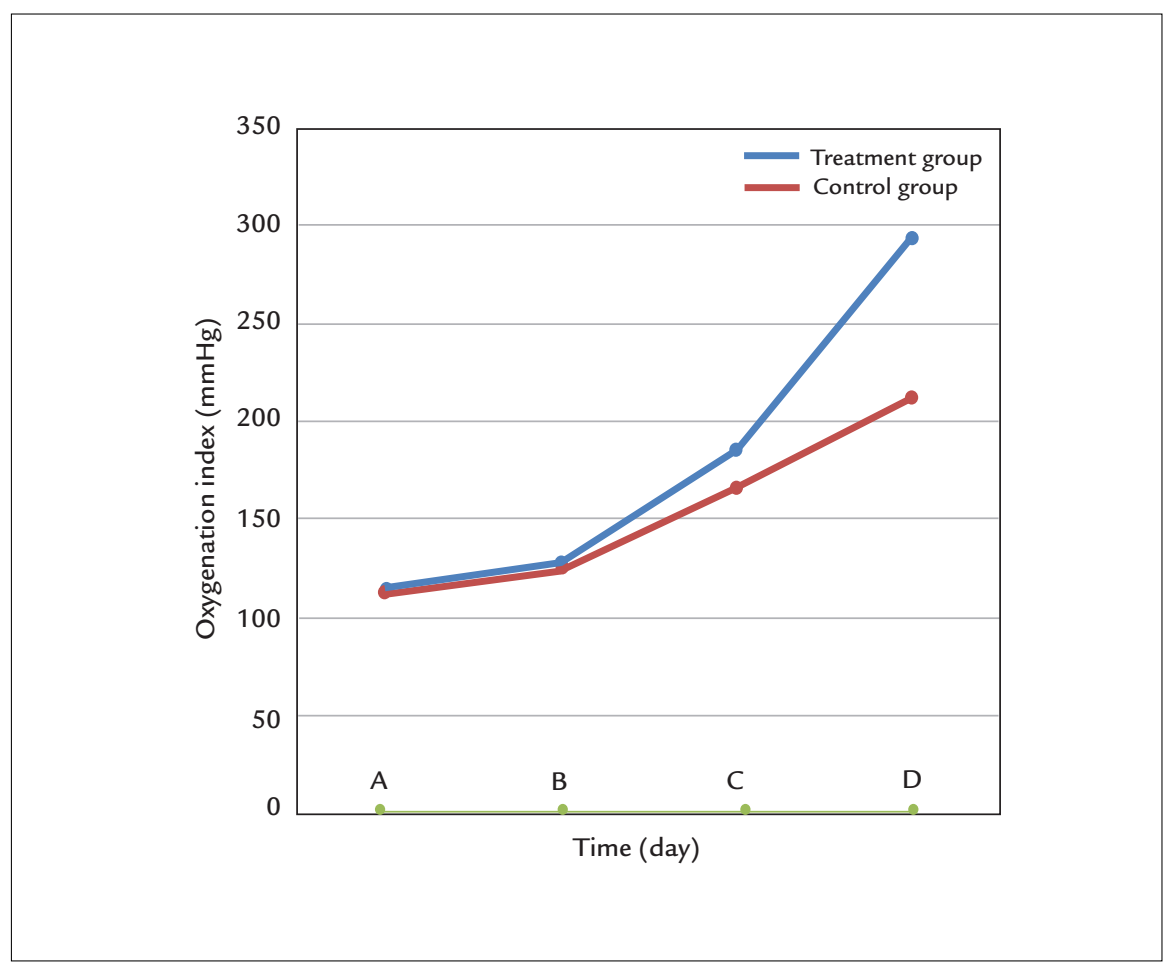

FIGURE 3 Changes in oxygenation index in patients before and after treatment between the two groups. A. Before treatment; B. Three days after treatment; $C$. Five days after treatment; D. Seven days after treatment. 
through persistent efforts, the mortality rate of ARDS in the United States and Europe decreased to $25-40 \%$. However, the prognosis of ARDS in China did not seem to improve to the same degree. An epidemiological survey of Beijing and Shanghai showed that the mortality rate of ARDS was as high as 50.0 and $68.7 \%$, respectively. ${ }^{1,4,5}$ Therefore, we must objectively evaluate treatment strategies for ARDS, and explore new methods of treatment.

High permeability pulmonary edema is induced by ACM injury and increased vascular permeability; the pathological basis is excessive systemic inflammatory response that induces pulmonary capillary permeability, interstitial pulmonary edema and alveolar ventilation/perfusion imbalance, leading to hypoxemia (mainly pulmonary diffusion dysfunction). In severe sepsis or early trauma, monocyte-macrophage system effector cells (especially macrophages) are activated. Many pro-inflammatory cytokines including tumor necrosis factor-alpha (TNF- $\alpha$ ), interleukin-1 $\beta$ (IL-1 $\beta$ ), IL-6, IL-8, histamine and leukotrienes are released and are involved in the inflammatory reactions of ARDS; of these, TNF- $\alpha$ is a key part of the cytokine network and an initiating factor of inflammation, as well as one of the main molecules causing damage to pulmonary vascular endothelial cells. Studies have shown that serum TNF- $\alpha$ and IL- $1 \beta$ in patients with ARDS are significantly increased; IL- $1 \beta$ and IL- 6 in bronchoalveolar lavage fluid are also significantly high. The IL- $1 \beta$ and IL- 6 concentration in bronchial lavage fluid was closely related to the severity and prognosis of ARDS. ${ }^{15,16}$

EVLW comprises intracellular fluid, alveolar fluid, and interstitial lung fluid. Due to less significant intracellular fluid changes, intra-alveolar and interstitial lung fluids reflect the severity of pulmonary edema. An increase in EVLW is one of the important characteristics in the pathophysiology of ARDS, and an important cause of refractory hypoxemia. Timely EVLW measurement can properly reflect ACM injury and the degree of pulmonary edema, and aids in the assessment of ARDS. Due to access limitations and potential trauma, lung biopsy is not feasible for routine clinical use. Thus, EVLW is more sensitive for the identification of ARDS pulmonary edema, and has good predictive value for treatment and prognosis. ${ }^{12-15}$

The main components in rhubarb include emodin, rhein, aloe vera and tannins. Rhubarb has purgative activity, and is said to "remove heat and toxic materials, cool the blood and alleviate congestion." The "Compendium of Materia Medica" indicated that rhubarb "alleviated congestion, cold and heat, breaking accumulation, flow draining abiding food, cleaning up the gastrointestinal, smoothing and helpful in water and italica digestion, neutralizing and digesting food, tuning five internal organs." Research has confirmed that rhubarb, similarly to calcium channel blockers, has a protective effect by preventing calcium overload in cells; however, calcium transmembrane flow and changes in cytosolic calcium are essential for the synthesis and release of inflammatory mediators. Rhubarb can protect cell structures, maintain close connections between cells and prevent the activation of polymorphonuclear neutrophils and macrophages, thus preventing the release of large amounts of proinflammatory mediators, thereby decreasing ACM damage, and reducing EVLW, improving pulmonary edema and pulmonary compliance, and improving oxygenation. ${ }^{17-21}$

Our study further showed that after treatment of ARDS with rhubarb for 5 to 7 days, the EVLW was significantly reduced, the PVPI decreased and oxygenation was also improved. In short, rhubarb can reduce EVLW in patients with ARDS to some extent, and improve oxygenation without obvious toxic side effects.

\section{ACKNOWLEDGMENTS}

This work was funded by Research Projects of Yiwu City, Zhejiang Province (12-3-01).

\section{Conflict of InTERest}

The authors declare no conflict of interest.

\section{References}

1. Janz DR, Ware LB. Approach to the patient with the acute respiratory distress syndrome. Clin Chest Med. 2014; 35(4):685-96.

2. Del Sorbo L, Slutsky AS. Acute respiratory distress syndrome and multiple organ failure. Curr Opin Crit Care. 2011; 17(1):1-6.

3. Calfee CS, Gallagher D, Abbott J, Thompson BT, Matthay MA; NHLBI ARDS Network. Plasma angiopoietin-2 in clinical acute lung injury: prognostic and pathogenetic significance. Crit Care Med. 2012; 40(6):1731-7.

4. Curley GF, Laffey JG. Future therapies for ARDS. Intensive Care Med. 2015; 41(2):322-6.

5. Duggal A, Ganapathy A, Ratnapalan M, Adhikari NK. Pharmacological treatments for acute respiratory distress syndrome: systematic review. Minerva Anestesiol. 2015; 81(5):567-88.

6. Huang PM, Lin TH, Tsai PR, Ko WJ. Intrapleural steroid instillation for multiple organ failure with acute respiratory distress syndrome. Shock. 2013; 40(5):392-7.

7. Zhang $\mathrm{Z}, \mathrm{Lu} \mathrm{B}, \mathrm{Ni} \mathrm{H}$. Prognostic value of extravascular lung water index in critically ill patients: a systematic review of the literature. J Crit Care. 2012; 27(4):420.e1-8.

8. Tonelli AR, Zein J, Adams J, Ioannidis JP. Effects of interventions on survival in acute respiratory distress syndrome: an umbrella review of 159 published randomized trials and 29 meta-analyses. Intensive Care Med. 2014; 40(6):769-87.

9. Seeley EJ. Updates in the acute respiratory distress syndrome. Definitions, epidemiology, pathogenesis, and treatment. Icu Director. 2012; 3(5):224-9.

10. Lin T. Combined treatment of traditional Chinese medicine and western medicine for acute respiratory distress syndrome after chest trauma. Chinese J Exp Tradit Med Formulae. 2013; 19:333-5.

11. Hao YH, Li WN, Xing JF. Treatment of traditional Chinese and Western medicine for 28 cases of acute respiratory distress syndrome after thoracic trauma. Contemp Med. 2012; 18:155-6.

12. Zhang Z, Ni H, Qian Z. Effectiveness of treatment based on PiCCO parameters in critically ill patients with septic shock and/or acute respiratory distress syndrome: a randomized. Intensive Care Med. 2015; 41(3):444-51. 
13. Kollef MH, Schuster DP. The acute respiratory distress syndrome. N Engl J Med. 1995; 332(1):27-37.

14. ARDS Definition Task Force, Ranieri VM, Rubenfeld GD, Thompson BT, Ferguson ND, Caldwell E, et al. Acute respiratory distress syndrome: the Berlin Definition. JAMA. 2012; 307(23):2526-33.

15. Levy MM, Fink MP, Marshall JC, Abraham E, Angus D, Cook D, et al. 2001 SCCM/ESICM/ACCP/ATS/SIS international sepsis definitions conference. Crit Care Med. 2003; 31(4):1250-6.

16. Friedland JS, Porter JC, Daryanani S, Bland JM, Screaton NJ, Vesely MJ, et al. Plasma proinflammatory cytokine concentrations, Acute Physiology and Chronic Health Evaluation (APACHE) III scores and survival in patients in an intensive care unit. Crit care Med. 1996; 24(11):1775-81.
17. Li XL. Research progress of Rhubarb in the treatment for acute critical illness. J Emerg Tradit Chinese Med. 2005; 14:1218-9.

18. Qu AJ, Wu TJ, Liu GQ. Effects of rhubarb TNF- $\alpha$, IL-1 and IL-6 in patients with SIRS and MODS. First Aid J Tradit Chinese Western Med. 2000; 7:43-5.

19. Liu F, Gao SJ, Hu HG, Wang JW, Zhang DP. Experimental study of Rhubarb in treatment for gastrointestinal dysfunction after shock. Chin J Crit Care Med. 2003; 23:38.

20. Tan SQ, Liu S. Research progress of the pharmacological effect of Rhubarb in emergency medicine and its applications. Med Recapitulate. 2012; 18:4231-4.

21. Wu B, Liu YJ, Lian L. Research progress of pharmacological effect of Rheum officinale. Chinese Med Modern Distance Education of China. 2015; 13:152-4. 